Original investigation

Open Access

\title{
Type-2 diabetes-induced changes in vascular extracellular matrix gene expression: Relation to vessel size WeiWei Song ${ }^{1}$ and Adviye Ergul ${ }^{* 1,2}$
}

Address: ${ }^{1}$ Program in Clinical and Experimental Therapeutics, the University of Georgia College of Pharmacy, Augusta, Georgia 30912, USA and ${ }^{2}$ Vascular Biology Center, Medical College of Georgia, Augusta, Georgia 30912, USA

Email: WeiWei Song - wsong@temple.edu; Adviye Ergul* - aergul@mail.mcg.edu

* Corresponding author

Published: 17 February 2006

Cardiovascular Diabetology2006, 5:3 doi:10.1 186/1475-2840-5-3

This article is available from: http://www.cardiab.com/content/5/I/3

(C) 2006Song and Ergul; licensee BioMed Central Ltd.

This is an Open Access article distributed under the terms of the Creative Commons Attribution License (http://creativecommons.org/licenses/by/2.0), which permits unrestricted use, distribution, and reproduction in any medium, provided the original work is properly cited.

\begin{abstract}
Background: Hyperglycemia-induced changes in vascular wall structure contribute to the pathogenesis of diabetic microvascular and macrovascular complications. Matrix metalloproteinases (MMP), a family of proteolytic enzymes that degrade extracellular matrix (ECM) proteins, are essential for vascular remodeling. We have shown that endothelin-I (ET-I) mediates increased MMP activity and associated vascular remodeling in Type 2 diabetes. However, the effect of Type 2 diabetes and/or ET-I on the regulation of ECM and MMP gene expression in different vascular beds remains unknown.
\end{abstract}

Methods: Aorta and mesenteric artery samples were isolated from control, Type 2 diabetic GotoKakizaki (GK) rats and GK rats treated with $\mathrm{ET}_{\mathrm{A}}$ antagonist $\mathrm{ABT}-627$. Gene expression profile of MMP-2, MMP-9, MTI-MMP, fibronectin, procollagen type I, c-fos and c-jun, were determined by quantitative real-time ( $q R T)$ PCR. In addition, aortic gene expression profile was evaluated by an ECM \& Adhesion Molecules pathway specific microarray approach.

Results: Analysis of the qRT-PCR data demonstrated a significant increase in mRNA levels of MMPs and ECM proteins as compared to control animals after 6 weeks of mild diabetes. Futhermore, these changes were comparable in aorta and mesentery samples. In contrast, treatment with $\mathrm{ET}_{\mathrm{A}}$ antagonist prevented diabetes-induced changes in expression of MMPs and procollagen type $I$ in mesenteric arteries but not in aorta. Microaarray analysis provided evidence that 27 extracellular matrix genes were differentially regulated in diabetes. Further QRT-PCR with selected 7 genes confirmed the microarray data.

Conclusion: These results suggest that the expression of both matrix scaffold protein and matrix degrading MMP genes are altered in macro and microvascular beds in Type 2 diabetes. $\mathrm{ET}_{\mathrm{A}}$ antagonism restores the changes in gene expression in the mesenteric bed but not in aorta suggesting that ET-I differentially regulates microvascular gene expression in Type 2 diabetes.

\section{Introduction}

Changes in vascular wall structure occur in diabetes and contribute to both micro- and macrovascular complica- tions. Previous studies in streptozosin (STZ)-induced model of Type 1 diabetes documented increased intimal proliferation and medial thickness as well as extracellular 
matrix (ECM) deposition in microvessels such as mesenteric arteries as early as 3 weeks of experimental diabetes [1-4]. Vascular remodeling and hypertrophy associated with augmented expression of dedifferentiation markers of vascular smooth muscle cells also occur in larger vessels like aorta [5]. While these studies provided evidence for diabetes-induced alterations in ECM synthesis and vascular structure of an experimental model of Type 1 diabetes that is characterized by highly elevated blood glucose levels, to what extent mild-to-modest hyperglycemia as seen in Type 2 diabetes influences the gene expression of ECM proteins associated with vascular remodeling and whether there are differences in micro vs macrovascular bed are not fully understood.

Vascular ECM proteins such as collagen type 1 and 3, fibronectin and thrombospondins not only function as scaffolding proteins but also involved in matrix signaling by interacting with integrin family of proteins and triggering growth-promoting signals. ECM displays a very dynamic equilibrium where there is constant synthesis, degradation and reorganization. Turnover of matrix proteins are regulated by matrix metalloproteinases (MMPs) [6]. While decreased MMP activity is generally believed to contribute to ECM accumulation in diabetic kidney and in vascular tissue from patients with diabetes, we and others have recently reported that there is an early activation of MMPs in hypertension and diabetes [7-9]. However, transcriptional regulation of ECM proteins and MMPs in different vascular beds and specifically in Type 2 diabetes remains to be determined.

Vasoactive factors including endothelin-1 (ET-1) and angiotensin II are involved in diabetic vascular remodeling as evidenced by studies that demonstrated attenuation of these responses by blockade of these systems in both experimental and clinical diabetes. For example, Gilbert and colleagues reported that $\mathrm{ET}_{\mathrm{A}}$ receptor antagonism prevents mesenteric vascular hypertrophy in Type 1 diabetes [4]. Another study provided evidence that blockade of ET-1 action inhibits ECM deposition in the aorta as well [5]. We recently reported that ET-1 levels are elevated and an $\mathrm{ET}_{\mathrm{A}}$ antagonist prevents $\mathrm{ECM}$ deposition and MMP activation in middle cerebral arteries but not in the kidney of Goto-Kakizaki (GK) rats, a non-obese Type 2 diabetes model $[9,10]$. Thus, this study was designed to test the hypothesis that there is a differential regulation of MMP activation in micro vs macrovessels in Type 2 diabetes and ET-1 contributes to this process.

\section{Methods}

\section{Animal and tissue preparation}

All experiments were performed on male Wistar (Harlan, Indianapolis, IN) and Goto-Kakizaki (in-house bred, derived from the Tampa colony) rats [11]. The animals were housed at the Medical College of Georgia animal care facility that is approved by the American Association for Accreditation of Laboratory Animal Care and study was approved by the Institutional Animal Care and Use Committee. Animals were fed standard rat chow and tap water ad-libitum. During housing, drinking water measurements, weight, and blood glucose measurements were performed twice weekly. At 12 weeks of age, when all GK animals became overtly diabetic, telemetry transmitters for blood pressure measurements were implanted as previously reported [12]. After a 2 week-recovery period, control and diabetic animals were administered the $\mathrm{ET}_{\mathrm{A}}$ selective antagonist, ABT-627 (5 mg/kg/day) in drinking water, or vehicle only [8]. Treatment was maintained until the time of sacrifice at 18 weeks of age. Animals were anesthetized with sodium pentobarbital and exsanguinated via the abdominal aorta. Upon sacrifice, the mesenteric

Table I: List of primers used in qRT-PCR

\begin{tabular}{|c|c|c|c|}
\hline Primer ID & Accession No & Sequence & Expect Size (bp) \\
\hline MMP-9 (F) & NM_031055 & GTC TTC CCC TTC GTC TTC CT & 117 \\
\hline MMP-9 (R) & & ACC CCA CTT CTT GTC AGC GT & \\
\hline MMP-I4 (F) & NM_03I056 & TGT CCC AGA TAA GCC CAG AA & 128 \\
\hline MMP-I4 (R) & & TAT TCC TCA CCC GCC AGA AC & \\
\hline GAPDH (F) & XM_234433 & AGC CCA GAA CAC CAT TCC TAC & 191 \\
\hline GAPDH (R) & & ATG CCT GCT TCA CCA CAT TC & \\
\hline FIBRONECTIN (F) & $\times 15906$ & GCA CAG GGG AAG AAA AGG AG & 189 \\
\hline FIBRONECTIN (R) & & TTG AGT GGA TGG GAG GAG AG & \\
\hline MMP-2 (F) & NM_031054 & GTG CCA AGG TGG AAA TCA GAG & 110 \\
\hline MMP-2 (R) & & AAG GTT GAA GGA AAC GAG CGA & \\
\hline Procollagen I (F) & Z78279 & AAG GGT GAG ACA GGC GAA CAA & 170 \\
\hline Procollagen I (R) & & TTG CCA GGA GAA CCA GCA GAG & \\
\hline$c-f o s(F)$ & XM_234422 & GTG GTG GAA GGC GTA TCG AGT TT & 102 \\
\hline c-fos (R) & & GTG TGA TGC CAG AAG CAG ATC CA & \\
\hline c-jun (F) & $\times 17163$ & CCT AGC TGA ACT GCA TAG CCA GAA & 177 \\
\hline c-jun (R) & & AAG TTG CTG AGG TTG GCG TAG A & \\
\hline
\end{tabular}


Table 2: Metabolic parameters of Control Wistar and GK rats.

\begin{tabular}{cccc}
\hline Metabolic Parameters & Control & GK & GK + ABT-627 \\
Body weight (g) & $502 \pm 11$ & $359 \pm 7^{*}$ & $379 \pm 29$ \\
Blood glucose (mg/d) & $116 \pm 5$ & $239 \pm 23^{*}$ & $211 \pm 18$ \\
Mean Arterial Pressure (MAP, mm Hg) & $101 \pm 2$ & $110 \pm 7$ & $112 \pm 1$ \\
\hline
\end{tabular}

$* \mathrm{P}<0.05$ vs control

bed was harvested, third order mesenteric arteries and thoracic aorta were isolated and immediately put into RNAlater $^{\mathrm{TM}}$ (Ambion, Austin, TX, USA) for storage at $80^{\circ} \mathrm{C}$.

\section{RNA isolation and CDNA synthesis}

Total RNA extraction was carried out using the RNeasy ${ }^{\otimes}$ Mini kit (Qiagen Inc., Valencia, CA) according to manufacturer's instructions. RNA quality from each sample was assured by the A260/280 absorbance ratio and by electrophoresis of $1.2 \%$ agarose formaldehyde gel. 1.0-2.0 $\mu \mathrm{g}$ of total RNA was reverse transcribed into single strand cDNA using MuLV reverse transcriptase (Applied Biosystems, Foster City, CA, USA). RT reaction was carried out for 60 min at $42^{\circ} \mathrm{C}$ and 5 min at $95^{\circ} \mathrm{C}$ in a thermocycler.

\section{Primer design and $q R T-P C R$}

All oligonucleotide primer sets were designed based upon published mRNA sequence. Expected amplicon lengths were from $100 \mathrm{bp}-200 \mathrm{bp}$. Oligonucleotide primers used in this study are listed in Table 1 . The qRT-PCR was performed in a SmartCycler II (Cepheid, Sunnyvale, CA) by using SYBR ${ }^{\circledast}$ Green PCR Master Mix (Applied Biosystems, Foster City, CA, USA). 2-2.5 $\mu$ of cDNA template was used for qRT-PCR in a final volume of $25 \mu \mathrm{l}$. CDNA was amplified according to the following condition: $95^{\circ} \mathrm{C}$ for $15 \mathrm{~s}$ and $60^{\circ} \mathrm{C}$ for $60 \mathrm{~s}$ from 40 to 45 amplification cycles. Fluorescence changes were monitored with SYBR Green after every cycle. Melting curve analysis was performed $\left(0.5^{\circ} \mathrm{C} / \mathrm{s}\right.$ increase from $55-95^{\circ} \mathrm{C}$ with continuous fluorescence readings) at the end of cycles to ensure that single PCR products were obtained. Amplicon size and reaction specificity were confirmed by $2.5 \%$ agarose gel electro- phoresis. All reactions were repeated in 3 separate PCR runs using RNA isolated from 3 sets of animals. Results were evaluated with the SmartCycler II software. Glyceraldehyde-3-phosphate dehydrogenase (GAPDH) primers were used to normalize samples. To monitor crossover contaminations of PCR, RNase-free water (Qiagen Inc., Valencia, CA) was included in the RNA extraction and used as a negative control. To ensure quality of data, a negative control was always applied in each run.

\section{cDNA gene expression array analysis}

The expression profile of extracellular matrix \& adhesion molecules genes was analyzed using the non-radioactive GEArray Q series Mouse gene array (MM-010N, SuperArray Bioscience Corp., Frederick, MD). This array membrane is composed of 96 extracellular matrix \& adhesion molecules genes, a plasmid pUC18 negative control, and four housekeeping genes including glyceraldehyde-3phosphate dehydrogenase (GAPDH), cyclophilin A, ribosomal protein L13a, and $\beta$-actin. Biotinylated cDNA probes were denatured and hybridized to extracellular matrix \& adhesion molecules gene-specific cDNA fragments spotted on the membranes. After pre-hybridization with GEAhyb Hybridization Solution (SuperArray) of denatured salmon sperm DNA (Invitrogen). The array membrane was hybridized with denatured cDNA probes overnight at $55^{\circ} \mathrm{C}$. Following washing the membrane twice with $2 \times$ SSC, $1 \%$ SDS and twice with $0.1 \times$ SSC, $0.5 \%$ SDS for $15 \mathrm{~min}$ at $55^{\circ} \mathrm{C}$ each, the membrane was blocked with GEAblocking Solution Q (SuperArray) for $40 \mathrm{~min}$ and incubated with alkaline phosphatase-conjugated streptavidin for $10 \mathrm{~min}$ at room temperature. Chemiluminescent detection was performed using CDP-

Table 3: qRT-PCR-based fold changes in gene expression in control vs diabetic GK rats treated with or without ABT-627.

\begin{tabular}{|c|c|c|c|c|}
\hline \multicolumn{3}{|c|}{ Aorta } & \multicolumn{2}{|c|}{ Mesenteric artery } \\
\hline & C vs GK & GK vs $G K+A B T 627$ & C vs GK & GK vs GK+ABT627 \\
\hline MMP-2 & $\uparrow 10^{*}$ & No change & 个II* & $\downarrow 3^{* * *}$ \\
\hline MMP-9 & $\uparrow 3^{*}$ & No change & $\uparrow 10^{*}$ & $\downarrow 2^{* *}$ \\
\hline MTI-MMP & $\uparrow 6^{*}$ & No change & $\uparrow 7^{*}$ & $\downarrow 7^{* *}$ \\
\hline COLIAI & $\uparrow 27^{*}$ & No change & $\uparrow 7^{*}$ & $\downarrow 8^{* *}$ \\
\hline Fibronectin & $\uparrow 1.23$ & $\downarrow 1.25$ & $\uparrow 9 *$ & $\downarrow 3^{* *}$ \\
\hline c-Fos & $\downarrow 3^{*}$ & $\uparrow 2$ & $\downarrow 3^{*}$ & $\uparrow 2^{* *}$ \\
\hline c-Jun & $\uparrow 3^{*}$ & No change & $\uparrow 3^{*}$ & $\downarrow 5^{* *}$ \\
\hline
\end{tabular}

$* \mathrm{p}<0.05 \mathrm{C}$ vs GK, ${ }^{* *} \mathrm{p}<0.05 \mathrm{GK}$ vs GK+ABT-627 

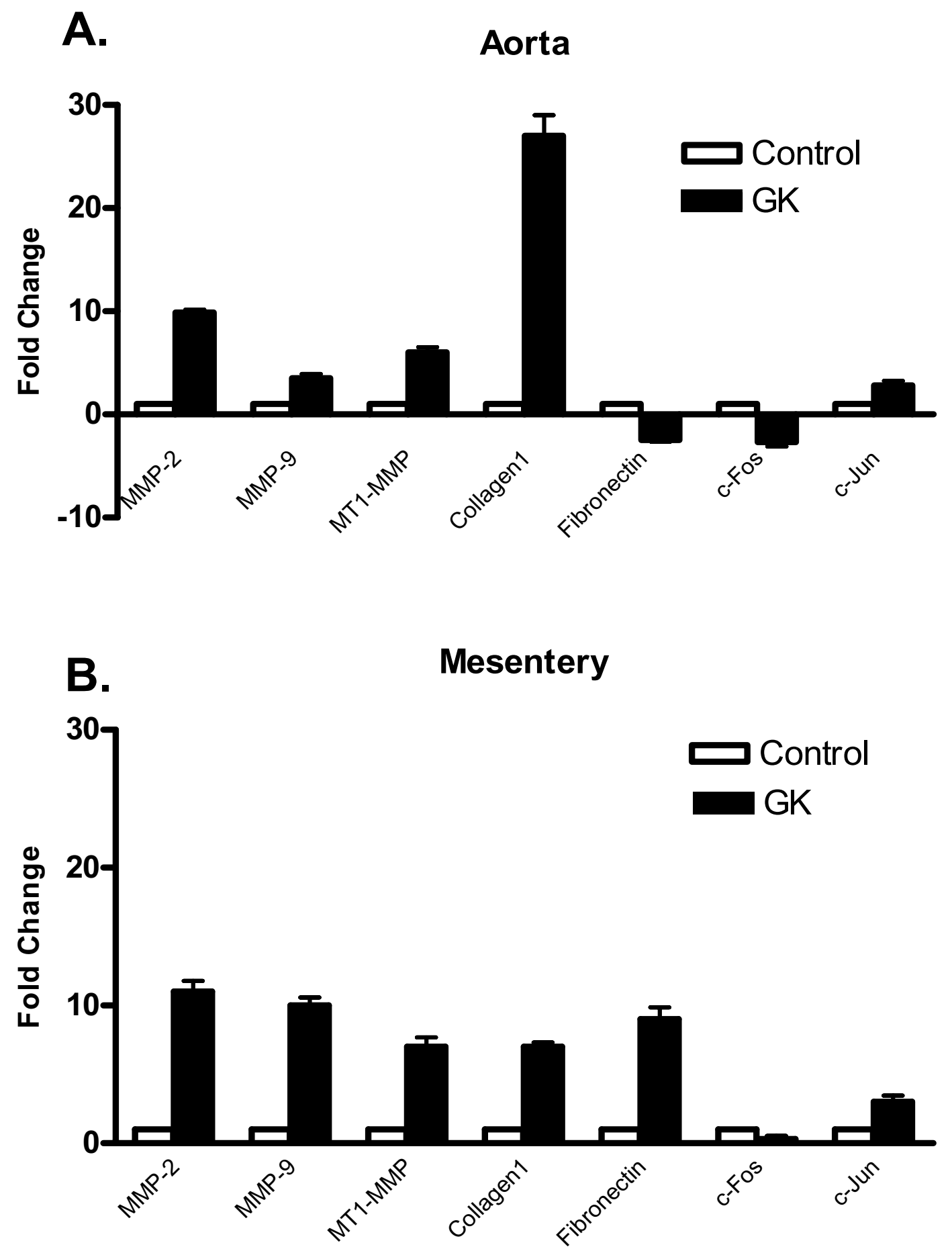

Figure I

qRT-PCR analysis of diabetes-induced alterations in ECM and MMP expression. 
Control

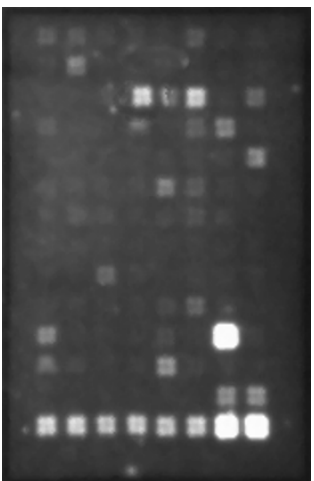

GK

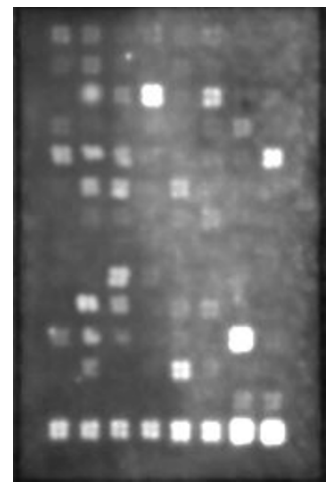

Figure 2

A representative image of extracellular matrix and adhesion molecular microarray of control and GK rats.

Star substrate. The results were analyzed with ScanAlyze and GEArray Analyzer. The relative expression levels of different genes were estimated by comparing its signal intensity with that of internal control $\beta$-actin.

\section{Data analysis}

RT-PCR results were reported as relative gene expression and the fold change in target genes was determined by $2^{-}$ $\Delta \Delta \mathrm{Ct}$ method, where $-\Delta \Delta \mathrm{Ct}=\left(\mathrm{C}_{\mathrm{tTarget}}-\mathrm{C}_{\mathrm{tActin}}\right)_{\mathrm{GK}}-\left(\mathrm{C}_{\mathrm{tTarget}}\right.$ $\left.\mathrm{C}_{\mathrm{tActin}}\right)_{\text {control }}$ and $\mathrm{Ct}$ value $=$ the cycle number that crosses signal threshold. To evaluate the effect of ABT-627 treatment on gene expression profile in the diabetic group, fold change was determined as $\left(\mathrm{C}_{\mathrm{tTarget}}-\mathrm{C}_{\mathrm{tActin}}\right)_{\mathrm{GK}}-\left(\mathrm{C}_{\mathrm{tTarget}}\right.$ - $\left.\mathrm{C}_{\text {tActin }}\right)_{\mathrm{GK}+\mathrm{ABT}-627}$. Group comparisons (C vs GK or GK vs GK +ABT-627) were performed using Student's t-test. For Array studies, relative gene expression was analyzed using the SAM (Statistical Analysis of Microarrays) software [13].

\section{Results and discussion}

GK rats displayed mildly elevated blood glucose levels that are representative of blood glucose levels seen in patients with Type 2 diabetes (Table 2). There were no significant changes in blood pressure and lipid profile. We have previously shown that GK rats are hypoinsulinemic and display impaired glucose tolerance. Euglycemic hyperinsulinemic clamp studies indicated that GK rats are also insulin resistant. These results strongly suggest that insulin resistance in GKs worsens impaired insulin secretion and leads to hypoinsulinemia as seen in a majority of patients with Type 2 diabetes that eventually become insulin-dependent and thus represent a clinically relevant model.

Since MMP-2, MMP-9 and MT1-MMP are major MMP species found in the vasculature and our previous studies suggested time-dependent differential regulation of MMPs in diabetes $[8,9,14-16]$, we first studied MMP and collagen gene expression in aorta and mesentery samples obtained from control and GK rats. Results summarized in Figure 1 demonstrated that mild elevation of blood glucose for 6 weeks is sufficient to stimulate gene expression of MMP-2, MMP-9 and MT1-MMP in both aorta and mesentery samples to a similar degree. Interestingly, collagen type 1 expression was higher in the aortic samples than in mesenteric vessels of diabetic animals. Fibronectin expression was unchanged in aorta but significantly increased in the mesentery. c-jun expression, which is involved in early growth response, was also increased whereas c-fos expression was lower in the diabetic group. To the best of our knowledge, these results are first to demonstrate increased MMP gene expression in small mesenteric arteries and in aorta in diabetes. We have recently reported that MMP protein and activity is increased in the middle cerebral arteries of GK rats and this is associated with vascular remodeling characterized by increased medial thickness and decreased lumen:media ratio [9]. Current findings strongly suggest that changes in enzyme activity parallel changes in gene expression indicating stimulation of the MMP system at transcriptional level in Type 2 diabetes. Our results are consistent with the previous reports that showed increased collagen expression in the mesenteric bed in Type 1 diabetes and further demonstrate that this increase is to a greater extent in large muscular vessels $[4,17,18]$. Our findings on fibronectin expression in aorta, however, differ from a recent report by Fukuda et al, who demonstrated a 4-fold increase in aortic fibronectin expression [5]. This difference may be attributed to the use of a model of Type 1 diabetes or the time point (26 weeks after the induction of diabetes) at which collagen expression was evaluated.

The role of local vasoactive factors in diabetic vascular remodeling has been an active area of research. Given that hyperglycemia stimulates the production of ET-1, the most potent vasoconstrictor with mitogenic and profibrotic properties, prompted studies with ET receptor antagonists to identify the involvement of the ET system in diabetic vascular complications [4,19-21]. However, a big majority of these studies were conducted using experimental models of Type 1 diabetes or obese animals. We have recently shown that ET-1 levels are elevated in the GK model [9]. Thus, the current study investigated the role of endogenous ET-1 on micro and macrovascular gene expression in the GK model. Results summarized in Table 3 demonstrate that blockade of the $\mathrm{ET}_{\mathrm{A}}$ receptor subtype early in the disease process does not prevent diabetes-induced increases in the expression of ECM proteins and MMPs in aorta. However, ET receptor antagonism completely attenuates increases in MT1-MMP and colla- 
Table 4: Microarray analysis of fold-changes in aortic gene expression in diabetes

\begin{tabular}{|c|c|c|c|c|c|}
\hline $\begin{array}{l}\text { Cell Adhesion } \\
\text { Molecules }\end{array}$ & & $\begin{array}{c}\text { Extracellular Matrix } \\
\text { Proteins }\end{array}$ & & Proteases & \\
\hline Integrin a2 & $4.1 \uparrow$ & Contactin I & $3.5 \uparrow$ & MMP2 & $3.6 \uparrow$ \\
\hline Integrin $a 2 b$ & $4.4 \uparrow$ & Collal & $24 \uparrow$ & MMP3 & $3.1 \downarrow$ \\
\hline Integrin a3 & $3.3 \uparrow$ & Thrombospondin 2 & $2.2 \downarrow$ & MMP9 & $8.7 \uparrow$ \\
\hline Integrin aL & $4.5 \uparrow$ & Thrombospondin 3 & $6.1 \uparrow$ & MMPIO & $7.0 \uparrow$ \\
\hline Integrin aM & $5.0 \uparrow$ & Thrombospondin 4 & $4.1 \uparrow$ & MMPII & $5.2 \uparrow$ \\
\hline Integrin b5 & $4.4 \uparrow$ & Vitronectin & $2.3 \uparrow$ & MMPI9 & $7.7 \uparrow$ \\
\hline Integrin b6 & $4.9 \uparrow$ & & & Cathepsin G & $2.8 \uparrow$ \\
\hline Ncam & $5.8 \uparrow$ & & & Cathepsin E & $3.5 \uparrow$ \\
\hline Ncam2 & $3.0 \uparrow$ & & & UPAR & $2.8 \downarrow$ \\
\hline Catenin a-like I & $2.8 \downarrow$ & & & & \\
\hline L-selectin & $5.3 \uparrow$ & & & & \\
\hline P-selectin & $4.1 \uparrow$ & & & & \\
\hline
\end{tabular}

gen type 1 expression and partially prevents changes in MMP-2, MMP-9 and fibronectin expression. These novel findings suggest that there is differential regulation of microvascular ECM gene expression in Type 2 diabetes. Our results confirm the findings of Gilbert et al. that $\mathrm{ET}_{\mathrm{A}}$ receptor blockade prevents microvascular hypertrophy in Type 1 diabetes and extends these results to Type 2 diabetes [4].

In order to determine whether expression of other ECM proteins is altered in the GK model, aortic gene expression profile was investigated using an ECM and Adhesion Molecules pathway specific microarray approach (Fig. 2). Genes that showed a significant change in the expression ( $p<0.05$ vs control) were grouped as adhesion molecules, ECM proteins and proteases in Table 4 and demonstrated that a total of 27 genes out of 96 genes were differentially regulated in GK rats. There were significant increases in various integrins and MMPs confirming our qRT-PCR results. Increased expression of adhesion molecules is important in diabetes not only to facilitate the adhesion and penetration of inflammatory cells but also to transmit the ECM-generated signals to underlying smooth muscle cells. We observed decreases in thrombospondin-2 (TSP2 ) but increases in TSP-3 and -4 expression and no change in TSP-1. These results are particularly interesting with regard to the interaction of TSP- 2 with MMP and other ECM proteins [22-24]. TSP-2 belongs to an extracellular glycoprotein family and it is involved in cell-matrix interactions including inhibition of MMP-2 by binding to the active protein as well as decreasing MMP expression [2426]. TSP-2 knock-out mice display defects in collagen fibril formation and attachment to ECM proteins. In this study we observed decreased TSP-2 and increased MMP-2 activation. Thus, it is reasonable to speculate that decreased TSP-2 expression may contribute to increased MMP-2 activation and decreased cell-matrix attachment resulting in a more free environment for vascular smooth muscle cells to migrate and remodel in diabetes. However, it has to be recognized that current studies involve only gene expression of ECM proteins and should be extended to the protein/activity level to be more definitive.

In conclusion, mild diabetes can stimulate a gene expression pattern that promotes remodeling of both micro and macrovessels. While ET-1 contributes to the alterations in gene expression profile in the microvasculature via activation of the $\mathrm{ET}_{\mathrm{A}}$ receptor subtype, changes in macrovascular gene expression are independent of ET-1.

\section{Authors' contributions}

WeiWei Song performed all the experiments and Adviye Ergul participated in all experimental aspects and preparation of the manuscript.

\section{Acknowledgements}

This work was supported by grants from NIH (HL076236-0I, DK074385), American Diabetes Association Research grant and Pfizer Atorvastatin Research Award to Adviye Ergul. The authors wish to thank Abbott Laboratories for the ABT627 compound.

\section{References}

I. Rumble JR, Cooper ME, Cox AJ, Soulis T, Wu L, Youssef S, Jasik M, Jerums G, Gilbert RE: Vascular hypertrophy in experimental diabetes: Role of advanced glycation end products. J Clin Invest 1997, 99(5): 1016-1027.

2. Cooper ME, Rumble J, Komers R, Du HC, Jandeleit K, Chou ST: Diabetes-associated mesenteric vascular hypertrophy is attenuated by angiotensin-converting enzyme inhibition. Diabetes 1994, 43(I0): I22I-I 228.

3. Vranes D, Cooper ME, Dilley RJ: Cellular mechanisms of diabetic vascular hypertrophy. Microvascular Research 1999, 57:8-18.

4. Gilbert RE, Rumble JR, Cao Z, Cox AJ, van Eeden P, Allen T], Kelly DJ, Cooper ME: Endothelin receptor antagonism ameliorates mast cell infiltration, vascular hypertrophy, and epidermal growth factor expression in experimental diabetes. Circ Res 2000, 86: $158-165$.

5. Fukuda G, Khan ZA, Barbin YP, Farhangkhoee H, Tilton RG, Chakrabarti S: Endothelin-mediated remodeling in aortas of diabetic rats. Diabetes Metab Res Rev 2005, 2 I(4):367-375.

6. Visse R, Nagase $\mathrm{H}$ : Matrix metalloproteinases and tissue inhibitors of metalloproteinases: structure, function, and biochemistry. Circ Res 2003, 92(8):827-839. 
7. Ammarguellat FZ, Gannon PO, Amiri F, Schiffrin EL: Fibrosis, matrix metalloproteinases, and inflammation in the heart of DOCA-salt hypertensive rats: role of $\mathrm{ET}(\mathrm{A})$ receptors. Hypertension 2002, 39(2 Pt 2):679-684.

8. Ergul A, Portik-Dobos V, Giulumian AD, Molero MM, Fuchs LC Stress upregulates arterial matrix metalloproteinase expression and activity via endothelin A receptor activation. Am J Physiol Heart 2003, 285(5):H2225-2232.

9. Harris AK, Hutchinson JR, Sachidanandam K, Johnson MH, Dorrance AM, Stepp DW, Fagan SC, Ergul A: Type 2 diabetes causes remodeling of cerebrovasculature via differential regulation of matrix metalloproteinases and collagen synthesis: role of endothelin-I. Diabetes 2005, 54(9):2638-2644.

10. Portik-Dobos V, Harris AK, Song W, Hutchinson J, Johnson MH, Imig JD, Pollock DM, Ergul A: Endothelin antagonism prevents early EGFR transactivation but not increased matrix metalloproteinase activity in diabetes. Am J Physiol 2006, 290(2):R435-44I

II. Standaert ML, Sajan MP, Miura A, Kanoh Y, Chen HC, Farese RV Jr, Farese RV: Insulin-induced activation of atypical protein kinase $C$, but not protein kinase $B$, is maintained in diabetic (ob/ob and Goto-Kakazaki) liver. Contrasting insulin signaling patterns in liver versus muscle define phenotypes of type 2 diabetic and high fat-induced insulin-resistant states. J Biol Chem 2004, 279(24):24929-24934.

12. Williams JM, Pollock JS, Pollock DM: Arterial pressure response to the antioxidant tempol and ETB receptor blockade in rats on a high-salt diet. Hypertension 2004, 44(5):770-775.

13. Tusher VG, Tibshirani R, Chu G: Significance analysis of microarrays applied to the ionizing radiation response. Proc Natl Acad Sci U S A 200I, 98(9):5II6-5I 2 I.

14. Galis ZS, Khatri J]: Matrix metalloproteinases in vascular remodeling and atherogenesis: the good, the bad, and the ugly. Circ Res 2002, 90(3):25I-262.

15. Portik-Dobos V, Anstadt MP, Hutchinson J, Bannan M, Ergul A: Evidence for a matrix metalloproteinase induction/activation system in arterial vasculature and decreased synthesis and activity in diabetes. Diabetes 2002, $51: 3063-3068$.

16. Ergul A, Portik-Dobos V, Hutchinson J, Franco J, Anstadt MP: Downregulation of vascular matrix metalloproteinase inducer and activator proteins in hypertensive patients. Am J Hypertens 2004, I 7(9):775-782.

17. Rumble JR, Cooper ME, Soulis T, Cox A, Wu L, Youssef S, Jasik M, Jerums G, Gilbert RE: Vascular hypertrophy in experimental diabetes. Role of advanced glycation end products. J Clin Invest 1997, 99(5): 1016-1027.

18. Gilbert RE, Cox A, McNally PG, Wu LL, Dziadek M, Cooper ME, Jerums G: Increased epidermal growth factor in experimenta diabetes related kidney growth in rats. Diabetologia 1997 , 40(7):778-785.

19. Wu S, Hopfner RL, McNeill JR, Wilson TW, Gopalakrishnan V: Altered paracrine effect of endothelin in blood vessels of the hyperinsulinemic, insulin resistant obese Zucker rat. Cardiovasc Res 2000, 45:994-1000.

20. Katakam PV, Pollock JS, Pollock DM, Ujhelyi MR, Miller AW: Enhanced endothelin-I response and receptor expression in small mesenteric arteries of insulin-resistant rats. Am J Physio 200I, 280(2): H522-527.

21. Hattori Y, Kasai K, Nakamura T, Emodo T, Shimoda S-I: Effects of glucose and insulin on immunoreactive endothelin-I release from cultured bovine endothelial cells. Metabolism 1991, 40:165-169.

22. Schroen B, Heymans S, Sharma U, Blankesteijn WM, Pokharel S, Cleutjens JP, Porter JG, Evelo CT, Duisters R, van Leeuwen RE, et al: Thrombospondin-2 is essential for myocardial matrix integrity: increased expression identifies failure-prone cardiac hypertrophy. Circ Res 2004, 95(5):515-522.

23. Bornstein $P$, Agah A, Kyriakides TR: The role of thrombospondins $I$ and 2 in the regulation of cell-matrix interactions, collagen fibril formation, and the response to injury. Int J Biochem Cell Biol 2004, 36(6): I I I5- I I25.

24. Spinale FG: Cell-matrix signaling and thrombospondin: another link to myocardial matrix remodeling. Circ Res 2004, 95(5):446-448.

25. Yang Z, Kyriakides TR, Bornstein P: Matricellular proteins as modulators of cell-matrix interactions: adhesive defect in thrombospondin 2-null fibroblasts is a consequence of increased levels of matrix metalloproteinase-2. Mol Biol Cell 2000, I I ( I0):3353-3364

26. Kyriakides TR, Zhu YH, Smith LT, Bain SD, Yang Z, Lin MT, Danielson KG, lozzo RV, LaMarca M, McKinney CE, et al.: Mice that lack thrombospondin 2 display connective tissue abnormalities that are associated with disordered collagen fibrillogenesis, an increased vascular density, and a bleeding diathesis. J Cell Biol 1998, I 40(2):419-430.
Publish with Biomed Central and every scientist can read your work free of charge

"BioMed Central will be the most significant development for disseminating the results of biomedical research in our lifetime. "

Sir Paul Nurse, Cancer Research UK

Your research papers will be:

- available free of charge to the entire biomedical community

- peer reviewed and published immediately upon acceptance

- cited in PubMed and archived on PubMed Central

- yours - you keep the copyright 